\title{
Microalbuminuria in Patients with Diabetes Mellitus: Prevalence and Associated Risk factors Title of your
}

\author{
Mahfoodh A Sulaiman,MBChB, HD \\ Family health center, \\ $\mathrm{DOH}$, \\ wasit, Iraq \\ Email@univ.com
}

\author{
Zhian S Ramzi \\ Family \& Community Medicine \\ Coloege of Medicine, Sulaimani University, \\ Sulaimani, Iraq \\ Zhiansalah2001@yahoo.com
}

\begin{abstract}
Microalbuminuria is the most leading cause for cardiovascular disease, diabetic nephropathy, end stage renal diseases, and death among diabetic patients. The study carried out to find out the prevalence of microalbuminuria in a sample of Sulaimani diabetics and to determine its relation to different associated risk factors. The first part of study was a cross-sectional study conducted through examination of records of diabetic patients registered in Sulaimani Diabetic Center from June 2010 to May 2012. The second part was a case-control study that conducted in the same center, including 50 cases of diabetics with positive microalbuminuria, and 50 controls with negative one, that were registered in the same center and matched by age and gender. A specially designed questionnaire was used by researcher to collect information from the records. SPSS version 21.0 was used for data analysis. Males accounts for half of cases and controls, highest proportion of sample was found among age group (6069) years about 34\%. The prevalence of microalbuminuria was 29\%. The study showed a statistical significant association of microalbuminuria with obesity, smoking, hypertension, retinopathy, ischemic heart disease, poor glycemic control, and dyslipidemia. In conclusion moderate prevalence of microalbuminuria was found among diabetic patients, the prevalence was more common in poor glycemic control, and hypertensive diabetics. There was significant relation between microalbuminuria and diabetic nephropathy.
\end{abstract}

Keywords: Microalbuminuria, diabetes mellitus, Sulaimani, prevalence.

\section{INTRODUCTION}

Increased level of microalbuminuria (MAU) is associated with increased risk of progressive kidney disease leading toward end stage renal disease (ESRD) [1]. MAU is a predictor of progressive renal damage, myocardial infarction and cardiovascular death (CV) [2]. The presence of MAU precedes the development of overt diabetic nephropathy (DN) by The American Diabetes Association (ADA)recommended that 20-40\% of type II diabetic patients with MAU without specific interventions, progress to overt nephropathy and 30-50\% of type I diabetic patients [3].

Microalbuminuria represents the earliest clinical evidence of DN. Screening and intervention programs should be implemented early. According to the ADA (2009) suggestions for screening and treatment of nephropathy, urine albumin excretion should be tested annually starting at diagnosis in all type I and type II diabetic patients [4]. In addition, treatment aimed to reduce albuminuria levels have been shown to reduce the risk for CV events [5], as well as kidney disease progression [6]. Several modifiable risk factors have been recognized for the development of MAU and for progression to $\mathrm{DN}$, such as hyperglycemia, dyslipidemia, hypertension, smoking, obesity, dietary factors, sedentary life style, heavy alcohol intake and genetic susceptibility [7]. MAU is a potentially useful marker of an increased of macrovascular disease. Nevertheless, progressively increasing albuminuria, or albuminuria accompanied by hypertension, is most likely to be due to early DN [8].

There were few studies regarding the prevalence of MAU and its associated risk factors in diabetic patients in Iraq. So this study was conducted to find out prevalence of MAU and their associated risk factors among type I and type II diabetic outpatients to those were attending the Sulaimani Center of Diabetes Mellitus and Endocrine (SCDMED)

\section{METHODS AND MATERIALS}

The study composed of two parts. The first part was a cross-sectional study conducted by examining the records of diabetic patients of both type I and II that were registered in the Sulaimani Center of Diabetes Mellitus and Endocrine Diseases (SCDMED) during study period from June 2010 to May 2012 to find out those with positive MAU.

The second part of study was a case-control study conducted during study period on patients registered in the center during that time. A sample of 100 participants was enrolled in this study, 50 cases of diabetic patients of both types, 25 male and 25 female, the controls composed of 50 diabetic patients of both types of DM with negative MAU. Cases and controls were matched by gender and age ( \pm 3 years). Collection of data was performed by direct interviews and reviewing of hospital registries in a specially designed questionnaire.

The study was approved by research ethics committee of College of Medicine. A verbal informed consent was obtained from both cases and controls before being interviewed. An official permission was obtained from 
the Directorate of Health of Sulaimani and the administration of SCDMED to carry out the study. The questionnaire included data on the age, gender, residency, occupation, type of diabetes, duration of diabetes, family history of diabetes, smoking status, alcohol intake, measurements of Height and weight.

The results of, glycated hemoglobin (HbA1C), MAU, serum cholesterol, and serum triglyceride (TG) were taken from laboratory of the center, and from the records; which were done to each diabetic patient routinely on subsequent visit to the SCDMED.

All diabetic patients registered in SCDMED, with positive MAU, who fulfilled the criteria of WHO, American Diabetic Association (ADA) by using the random urine test was using the DCA Vantage Analyzer(SIEMENS), the results of MAU test are measured as milligram $(\mathrm{mg})$ of protein leakage equal to that over 24 hours. Generally, less than 30mg is regarded as normal, 30-300 mg indicate early kidney disease and more than $300 \mathrm{mg}$ indicates advanced kidney disease (macroalbuminuria) [9]. HbA1c test for assessing glycaemic control in people with diabetes, HbA1c results were categorized as two groups as; $\leq 6.5$ as normal and $>6.5$ as poor glycemic control [10]. Participants were asked about quantity, was evaluated by pack-year (high exposure > 33 pack-year and low exposure $<33$ pack-year) [11].

Data analysis was performed using statistical package for social sciences (SPSS, version 21), Chi-square $(\chi 2)$ test was used to compare between the proportions and Ttest to compare means. $\mathrm{P} \leq 0.05$ was considered statistically significant.

\section{RESULTS}

The total number of diabetic patients of (both types I and II); that were registered in the Center during study period were (3158). All the records (3158) were examined for the MAU and the numbers of positive MAU were (916) giving a prevalence of MAU of $29 \%$ in both types of D.M (60\% were among type II and $40 \%$ were among type I ).

Table 1. Age group of MAU cases and controls

\begin{tabular}{|c|c|c|c|c|c|}
\hline \multirow{2}{*}{$\begin{array}{c}\text { Age } \\
\text { groups }\end{array}$} & \multicolumn{2}{|c|}{ Cases } & \multicolumn{2}{c|}{ Controls } & \multirow{2}{*}{ Total } \\
\cline { 2 - 6 } & No. & $\%$ & No. & $\%$ & \\
\hline $39-40$ & 1 & 2 & 2 & 4 & 3 \\
\hline $40-49$ & 8 & 16 & 7 & 14 & 15 \\
\hline $50-59$ & 11 & 22 & 12 & 24 & 23 \\
\hline $60-69$ & 17 & 34 & 17 & 34 & 34 \\
\hline $70-80$ & 13 & 26 & 12 & 24 & 25 \\
\hline Total & 50 & 100 & 50 & 100 & 100 \\
\hline
\end{tabular}

A total of 100 participants were involved in this study, (50 cases, and 50 controls); Cases with MAU have a mean \pm SD age of $60.5011 .30 \pm$ years (ranged from 30 to 80 years) and the controls have a mean \pm SD age of $60.44 \pm 11.13$ years (ranged from 30 to 80 years). In both cases and controls males constituted $50 \%$ of the sample. Sixty percent of cases were in the 7 th to 8 th decades of life with the highest rate in those in the 7 th decade (Table 1).

Obesity was reported by $77.1 \%$ of cases in comparison with $22.8 \%$ of controls and the difference was highly significant $(\mathrm{P}<0.001)$. Smoking was significantly higher among cases were about $78.6 \%$, while in controls were $21.4 \%$ only $(\mathrm{P}<0.001)$. Hypertension was significantly more prevalent in cases with MAU about $73.7 \%$ than controls about $26.3 \%$, and the difference was highly significant $(\mathrm{P}<0.001)$. Diabetic Retinopathy was more prevalent in cases with positive MAU about $96.4 \%$ compared to $3.6 \%$ in controls, and the difference was highly significant $(\mathrm{P}<0.001)$. In cases with MAU $75.9 \%$ of the patients had IHD, compared to $24.1 \%$ in control group and the difference was significant $(\mathrm{P}<0.001)$. There was no significant association between duration of D.M $(\mathrm{P}=0.579)$ and family history of D.M $(\mathrm{P}=0.274)$ among cases and controls in this study (Table 2).

Table 2. Some associated risk factors of MAU.

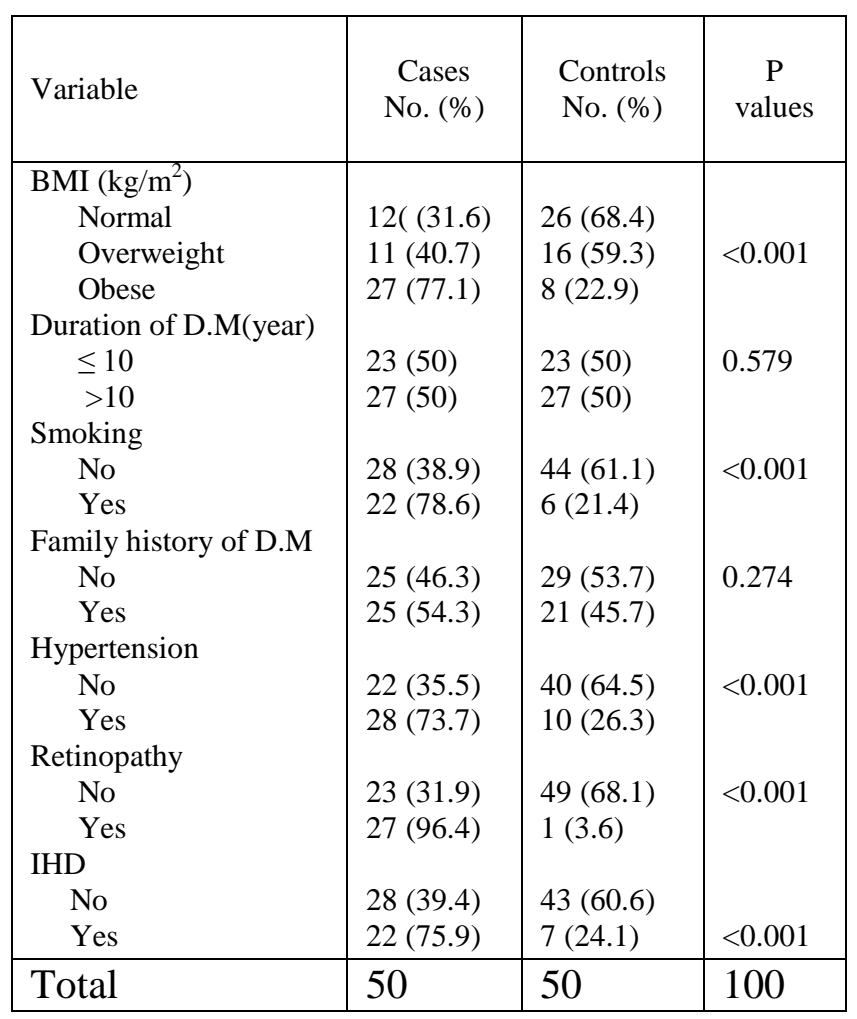

All cases of MAU had poor glycemic control compared to only $19.4 \%$ of control, so the difference was statistically highly significant $(\mathrm{P}<0.001)$. Approximately $80 \%$ of the cases had high TC ( $\geq 200 \mathrm{mg} / \mathrm{dl})$, compared to around fifth of control group and the difference was highly significant $(\mathrm{P}<0.001)$. In $72.4 \%$ of cases with MAU had high TG $(\geq 150 \mathrm{mg} / \mathrm{dl})$, while only $27.6 \%$ of 
control had high TG and the difference was statistically significant $(\mathrm{P}<0.004)$ (Table 3$)$.

Table 3. HbA1C, TC, and TG by cases and controls.

\begin{tabular}{|c|lc|cc|l|}
\hline Variable & \multicolumn{2}{|c|}{ Cases } & \multicolumn{2}{c|}{ Controls } & P \\
& No. & $\%$ & No. & $\%$ & values \\
\hline HbA1C (\%) & & & & & \\
$\leq 6.5$ & 0 & 0.0 & 38 & 100.0 & $<0.001$ \\
$>6.5$ & 50 & 80.6 & 12 & 19.4 & \\
TC(mg/dl) & & & & & \\
$<200$ & 19 & 31.1 & 42 & 68.9 & $<0.001$ \\
$\geq 200$ & 31 & 79.5 & 8 & 20.5 & \\
TG(mg/dl) & & & & & \\
$<150$ & 29 & 40.8 & 42 & 59.2 & 0.004 \\
$\geq 150$ & 21 & 72.4 & 8 & 27.6 & \\
\hline Total & 50 & & 50 & & 100 \\
\hline
\end{tabular}

The mean level of HbA1C in cases $(11.482 \pm 2.08)$ was significantly higher than the mean HbA1C among controls $(6.478 \pm 0.76)$; and the difference found statistically highly significant $(\mathrm{P}<0.001)$. Similarly, the mean level of TC in cases $(217.48 \pm 39.002)$ was significantly higher than the mean of TC among controls $(186.02 \pm 33.54)$; and the difference was highly significant $(\mathrm{P}<0.001)$. The mean level of $\mathrm{TG}$ in cases $(200.84 \pm 89.76)$ was significantly higher than the mean of TG among controls $(144.92 \pm 53.05)$; the difference statistically was highly significant $(\mathrm{P}<0.001)$, as shown in Table 4.

Table 4: Comparison of the Mean levels of some biochemical parameters by cases and controls

\begin{tabular}{|l|c|c|c|c|}
\hline $\begin{array}{c}\text { Parame } \\
\text { ters }\end{array}$ & $\begin{array}{c}\text { Controls } \\
\text { Mean } \pm \text { S.D }\end{array}$ & $\begin{array}{c}\text { Cases } \\
\text { Mean } \pm \text { S.D }\end{array}$ & $\begin{array}{c}\text { T- } \\
\text { test }\end{array}$ & $\begin{array}{c}\text { P } \\
\text { values }\end{array}$ \\
\hline HbA1C & $6.48 \pm 0.76$ & $11.48 \pm 2.08$ & 15.89 & $<0.001$ \\
MAU & $15.66 \pm 6.03$ & $122.5 \pm 86.74$ & 8.69 & $<0.001$ \\
TC & $186.02 \pm 33.54$ & $217.5 \pm 39.002$ & 4.32 & $<0.001$ \\
TG & $144.92 \pm 53.05$ & $200.8 \pm 89.76$ & 3.79 & $<0.001$ \\
& & & & \\
& & & & \\
\hline
\end{tabular}

\section{DISCUSSION}

The prevalence of MAU of was found to be $29 \%$, which is higher when compared with other studies done in Egypt (12\%) [12], Thailand (19\%) [13], USA (19\%) [14], France (9\%) [15], and Sweden (13\%) [16]. While higher prevalence of $36.3 \%$ was reported by an Indian study [17]. This variation in the prevalence of MAU rate can be attributed to several factors such as: Differences in populations, variability in the sample size, difference in the degree of glycemic control, the definition of MAU, the methods of measurement of MAU and urine collection, and the stage of the disease and ethnicity [18]. In present study obesity had highly significant association with MAU, which is in agreement with Moroccan study (Habbal et al) [19], while there was no relation between positive MAU and obesity in an Indian study [20].

No significant association was found with duration of DM, while other studies confirmed that the duration of diabetes is of the most important risk factors for the development of diabetic nephropathy [21].

In the current study, significant association was found with high blood pressure, which was in agreement with other studies [17, 22] which showed that high blood pressure increased the risk of developing of nephropathy therefore, hypertension can cause MAU and can accelerate the progression of diabetic nephropathy [23].

The results shows highly significant correlation between smoking and positive MAU which is consistent with other studies [24-25] and another study indicated that smoking status is not only a predictor of nephropathy but also an important predictor of the change in DNA oxidation in type II diabetic patients with MAU [26]. This study showed that MAU significantly increases the risk for development and progression of diabetic retinopathy in diabetic patients; even after adjustment for duration of diabetes, one of the most important predictors of diabetic retinopathy, and other comorbid conditions. Diabetic retinopathy and nephropathy seem to progress in a parallel manner. This may be because diabetic retinopathy shares similar pathophysiologic features with diabetic nephropathy through alterations in the microvasculature of retina and kidney [27].

The significant relation between the prevalence of MAU and with $\mathrm{HbA} 1 \mathrm{c}$ levels in current study was consistent with the findings from a study in Iran [28]. The level of glycemic control is most likely the dominant factor in the occurrence of MAU each $1 \%$ increase in $\mathrm{HbA1c}$ was associated with an $11 \%$ greater chance of developing MAU [29], TC and TG had highly significant relation with MAU, this fact was approved by other studies were MAU has been considered a marker of endothelial damage and is associated with higher prevalence of diabetes, hypertension, metabolic syndrome, renal dysfunction, and with an increased risk for cardiovascular diseases [30-31].

\section{CONCLUSION}

Microalbuminuria was common in this study, nearly present in third of diabetic cases and was highest among type II DM and was significantly associated with poor glycemic control, hypertension, retinopathy, obesity and dyslipidemia.

\section{REFERENCE}

[1] A. Kassab, T. Ajmi, M. Issaoui, L. Chaeib, A. Miled, M. Hammami, "Homocysteine enhances LDL fatty acid peroxidation, promoting microalbuminuria in type 2 diabetes," Annals of Clinical Biochemistry, vol. 45, pp. 476-80, 2008.

[2] YW. Ho, KF. Chau, CB. Leung, "Hong Kong registry report 2004, Hong Kong Journal of 
Nephrology, vol. 7, pp. 38-46, 2005.

[3] American Diabetes Association, "Nephropathy in diabetes (position statement)," Diabetes Care, vol. 27, pp. 79-83, 2004.

[4] American Diabetes Association, "Standards of medical care in diabetes - 2009 (position statement)," Diabetes Care, vol. 32, pp. S13-61, 2009.

[5] FW. Asselbergs, GF. Diercks, HL. Hillege, "Effects of fosinopril and pravastatin on cardiovascular events in subjects with microalbuminuria," Circulation, vol. 110, pp. 2809-16, 2004.

[6] HH. Parving, H. Lehnert, J. Brochner-Mortensen, R. Gomis, S. Andersen, P. Arner, "The effect of irbesartan on the development of diabetic nephropathy in patients with type 2 diabetes,' New England Journal of Medicine, vol. 345, pp. 870-8. 2001.

[7] Microalbuminuria Collaborative Study Group, "Effect of Captopril on progression to clinical proteinuria with insulin-dependent diabetes mellitus andmicroalbuminuria," Journal of the American Medical Association, vol. 271, pp. 275-9, 1994.

[8] BM. Frier, M. Fisher, "Diabetes Mellitus. In: Niki R. Colledge, Brian R. Walker, and Stuart H. Ralston. Davidson's principles and practice of Medicine," 21st Edition. Edinburgh: CHURCHILL LIVINGTONE ELSVIER, vol. 39, pp. 1360, 2010.

[9] American Diabetic Association, "Clinical Practice Recommendations,” Diabetes care, vol. 31, Suppl $1,2008$.

[10] World Health Organization, "Definition, Diagnosis and Classification of Diabetes Mellitus and its Complications Part 1: Diagnosis and Classification of Diabetes Mellitus. WHO/NCD/NCS/99.2 ed, Geneva, World Health Organization, 1999.

[11] LD. Silva, TH. Ginter, T. Forbush, N. Nokes, B. Fay, T. Mikuls, et al., "Extraction and Quantification of Pack-year and Classification of Smoker Information in Semi-structured Medical," Records Appearing in Proceedings of the 28th International Conference on Machine Learning, Bellevue, WA, USA., pp. 2-4, 2011.

[12] MY. Ahmedani, MZI. Hydrie, A. Iqbal, A. Gul, WB. Mirza, A. Basit, "Prevalence of microalbuminuria in type 2 diabetic patients in Karachi-Pakistan. A multicenter study," Journal of the Pakistan Medical Association, vol. 55, pp. 382-62005.

[13] A. Al-Kassab, W. Herman, T. Thompson, "Albuminuria is an uncommon complication of diabetes in Egypt," Diabetes, vol. 46, pp. 326 A, 1997.

[14] Thi Multicenter research group on diabetes, "Vascular complications in NIDDM in
Thailand," Diabetes Res Clin Part, vol. 25, pp. 61-9, 1994.

[15] R. Klein, BE. Klein, SE. Moss, MD. Davis, DL. DeMets, KJ. Cruickshanks, et al., "The Wisconsin epidemiologic study of diabetic retinopathy-III prevalence and risk of diabetic retinopathy when age at diagnosis is 30 years or more, Arch Ophthalmol, vol. 102, pp. 527-32, 1984.

[16] C. Delcourt, F. Vauzelle-Kervroeddn, G. Cathelineau, L. Papoz, "Low prevalence of longterm complication in NIDDM in France: A multicenter study," J Diabetes Complications, vol. 12, pp. 88-95, 1998.

[17] A. Varghese, R. Deepa, M. Rema, V. Mohan, "Prevalence of microalbuminuria in type 2 diabetes mellitus at a diabetes center in southern India," Postgraduate Medical Journal, vol. 77, pp. 399-402, 2001.

[18] DJ. Newman, MB. Mattock, AB. Dawnay, S. Kerry, A. McGuire, M. Yaggob, et al., "Systematic reviews on urine albumin testing for early detection of diabetic complication," Health Technology Assessment, vol. 9, pp. 163, 2005.

[19] R, Habbal, AR. Sekhri, M. Volpe, i- Search Investigators, "Prevalence of microalbuminuria in hypertensive patients and its associated cardiovascular risk in clinical cardiology: Moroccan results of the global i-SEAR $\mathrm{CH}$ survey - a sub-analysis of a survey with 21050 patients in 26 countries worldwide," Cardiovascular J Afr, vol. 21, pp. 200-205, 2010.

[20] N. K. Chowta, P. Pant, M. N. Chowta, Deep Dutta, Subhadib C, Satinath $M$, et al., "Indian J Nephrol," vol. 19, pp. 53-56, 2009.

[21] M. Yvonne, O'. Meara, R. Hugh, B. Brady, M. Barry, et al., "Diabetic Nephropathy. In : Braunwald E, Fausi As, Kasper DL, eds," Harrison's Principles of internal medicine, New York: McGraw-Hill, pp. 1590-1. 2001.

[22] M. Svensson, G. Sundkvist, HJ. Arnqvist, E. Bjork, G. Blohme, J. Bolinder, et al., "Signs of nephropathy may occur early in young adults with diabetes despite modern diabetes management: results from the nationwide population-based Diabetes Incidence Study in Sweden (DISS),' Diabetes Care, vol. 26, pp. 2903-9, 2003.

[23] M, Afkhami-Ardekani, M. Modarnesi, E., "Amirichaghmaghi. Prevalence of microalbuminuria and its risk factors in type 2 diabetic patients," Indian Journal of Nephrology, vol. 18, pp. 112, 2008

[24.] G, Biesenbach, P. Grafinger, O. Janko, J. Zazgornik, M. Regalado, S. Yang, et al., "Influence of cigarette-smoking on the progression of clinical diabetic nephropathy in type 2 diabetic patients," Clin Nephrol, vol. 48, 
pp. 146-150, 1997.

[25] G. Gambaro, G. Bax, M. Fusaro, M. Normanno, SM. Manani, M. Zanella, et al., "Cigarette smoking is a risk factor for nephropathy and its progression in type 2 diabetes mellitus," Diabetes Nutr Metab,; vol. 14, pp. 337-342, 2001.

[26] E. Ritz, H. Ogata, SR. Orth, A. Stefanski, RW. Schrier, E. Richard, et al., "Smoking: a factor promoting onset and progression of diabetic nephropathy," DiabetesMetab, vol. 26, pp. 5463, 2000.

[27] R. Klein, BE. Klein, SE. Moss, LP. Aielo, MT. Chahil, JS. Wong, et al., "Epidemiology of proliferative diabetic retinopathy," Diabetes Care, vol. 15, pp. 1875-1891, 1992.

[28] M. Shekiba, M. Afkhami-Ardekani, AM. Orafa, "The prevalence of micro and macroalbuminuria in diabetic patients referring to diabetes research center," Journal of Shahid Sadoughi University of Medical Sciences and Health Services, vol. 10, pp. 20-4, 2003.

[29] JH. Warram, JE. Manson, AS. Krolewski, "Glycosy-lated hemoglobin and the risk of retinopathy in insulin-dependent diabetes mellitus," New England Journal of Medicine, vol. 332, pp. 1305-6, 1995.

[30] MT. Pruijm, G. Madeleine, WF. Riesen, M. Burnier, P. Bovet, L. Bankir, et al., "Prevalence of microalbuminuria in the general population of Seychelles and strong association with diabetes and hypertension independent of renal markers," J Hypertens, vol. 26, pp. 871-7, 2008.

[31] D. De Zeeuw, HH. Parving, RH. Henning, RO. Gans, DE. Grobbee, WM. Janssen, et al., "Microalbuminuria as an early marker for cardiovascular disease," J Am Soc Nephrol, vol. 17, pp. 2100-5, 2006. 